DOI: https://doi.org/10.47405/mjssh.v6i10.1089

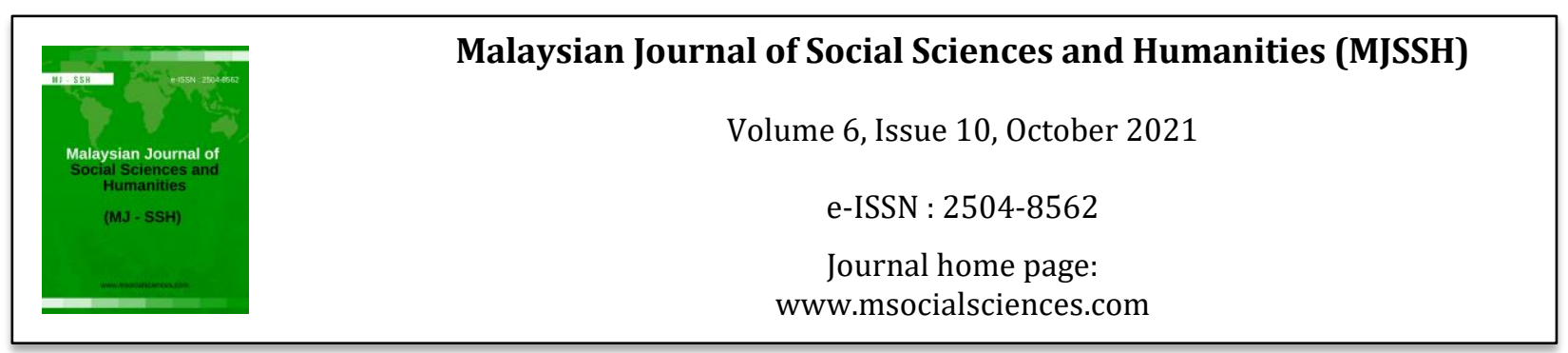

\title{
Factors Affecting Online Purchase Intention: A Case Study of Malaysian Consumers
}

\author{
Mohd Zulfakar Mohd Nawi' ${ }^{1}$, Samihatunnadzirah Sulaiman ${ }^{2}$ \\ 1Department of Professional Education and Postgraduates, Faculty of Technical and Vocational Education, Universiti \\ Tun Hussein Onn Malaysia (UTHM), Malaysia \\ ${ }^{2}$ Program Seni Kulinari, Kolej Komuniti Rompin, Malaysia
}

Correspondence: Mohd Zulfakar Mohd Nawi (zuy.mzmn@gmail.com)

\begin{abstract}
Online purchase is chosen as an easy step to spend on getting our essentials without having to line up at the counter. The objective of this research is to study online purchasing practices and the factors that influence them. In addition, the study also aims to examine the differences in online purchasing practices by selected background factors (gender, stratum, generation, ethnicity, home income, education level and zone). The population of this study consisted of users over the age of 17 who were selected by convenience through the 'mall intercept' method. T-test results showed significant differences $(t=-3.156, p=0.001)$ for online purchase practice scores between male and female respondents. ANOVA test results also show significant average score differences in terms of generation $[\mathrm{F}(3,1298)=3,475, \mathrm{p}=0.016]$, ethnicity $[\mathrm{F}(4,1291)=3,678, \mathrm{p}=0.006]$, and income $[\mathrm{F}$ $(4,1227)=6,935, \mathrm{p}=0.000$ ] while no differences are reported for the level of education, zone and stratum when $p>0.05$. The findings also show that only five key factors were the consumer choice before make online purchases, which are safety factors, products offered, risks, can trusted and user experience.
\end{abstract}

Keywords: online purchase, factors influencing, online shopping behavior

\section{Introduction}

The Internet become the part of today's consumer life. In keeping with the changing lifestyle, some consumers are now making the internet one of the mediums for buying goods and services. Online purchases are chosen as an easy step to spend on getting essentials without having to line up at the counter. In some economically developed countries, internet purchases have long been practiced and this trend is growing among local people. Through online purchases buyers can see what they want to buy, make comparisons in terms of price, quality and brand before booking.

According to a study conducted by the Malaysian Department of Statistics involving 31,433 households covering 96,225 individuals aged 15 and above found that 56 percent of respondents used computers. The findings also revealed that 57 percent also used the internet with a frequency of internet use at least once a day $(60.3 \%)$ while 94.2 percent of respondents surveyed using mobile phones. In terms of goods and services purchased over the internet, it consisted of clothing, bags and shoes (50.4\%), food and beverages (49.7\%), travel and travel products (35.4\%), accommodation services $(28.7 \%)$ and jewelry accessories self $(27.9 \%)$. 
PayPal's online payment agency report in collaboration with Nielsen Company researchers revealed that in 2010 only about 1.1 million Malaysians were willing to spend an average of RM 2,461 on online product purchases (Harian Metro, 2013). Meanwhile, the 2013/2014 Economic Report says the number of internet users in Malaysia is expected to increase to 25 million by 2015 compared to 18 million in 2012. Statistics also show that more internet users in Malaysia are buyers than sellers with the size of the online transaction market in Malaysia expected to reach RM 5 billion by 2014 compared to RM 1.8 billion in 2010. According to the report, Malaysia is one of the three core countries in Asia for average online spending over the last 12 months and is driven by travel services, predominantly flight tickets and hotel reservations. Therefore, based on current developments, this research aims to study online purchasing practices and factors that influenced it. In addition, the study also aims to examine the differences in online purchasing practices by selected background factors such as gender, stratum, generation, ethnicity, household income, education level and zone.

\section{Literature Review}

Online purchases are a trend in today's society since the use of the internet increased over the last 10 years. Goods and services sold online using various medium such as Shopee, Lazada, Carousell, Mudah.my, social media applications namely Facebook, Twitter, Instagram, website and advertised in a specific individual or group blog. Its main purpose is to attract users to browse and buy goods or services offered by sellers. In addition, internet purchases have been simplified with electronic payments through online banking or credit cards. According to the 2013/2014 Economic Report from Ministry of Finance (2014) the increasing number of internet users and online buyers reflects the broad market potential for online businesses. In addition, it is important for businesses to focus on mobile phone customers as their numbers are far above internet users. Reports also say that Malaysians spend more time surfing the internet than other media such as television, radio and newspapers with widespread use of the internet for social networks. In addition, the social network penetration rate is 91 percent with one of the three minutes used online for social networks. Reports also revealed that 11.8 million Malaysians are estimated to have a Facebook account with over 80 percent browsing the internet to access Facebook (Ministry of Finance, 2014).

Many studies have been conducted on online purchasing behavior. Based on recent studies, the characteristics and goals of individuals are found to influence behaviors such as purchasing activities, the intention to review the site and the attitude towards the site (Wu, 2003). In a study conducted by Mohd Suki in 2006 found that online buyers in Malaysia are made up of young, luxury, high-educated and wealthy people. However, in terms of gender, the income earned is varied across the years, where male respondents are more likely to make purchases (Li, Kuo \& Russell, 1999; Stafford, Turan \& Raisinghani, 2004) and spend more money online than women (Susskind, 2004). In addition, women are also less satisfied with online purchases and men are more obsessed with online purchases (Rodgers \& Harris, 2003). This is because women express the need for touch elements to evaluate a product before a purchase is made (Citrin, Stem, Spangenberg \& Clark, 2003). Other findings also indicate that men, higher education and higher income groups are more likely to buy online than women, lower education levels and low-income groups (Forsythe \& Shi, 2003; Swinyard \& Smith, 2003).

Most studies also try to identify factors that influence online purchasing behavior by focusing on different factors in different ways ( $\mathrm{Li} \&$ Zhang, 2002). According to the investigation report on the use and disclosure of ICT by individuals and households in Malaysia from Department of Statistics Malaysia (2021) there are three main reasons internet users do not buy or order goods or services over the internet because they are not interested $(69.5 \%)$ more interested in buying in a regular store $(49.1 \%)$ and lack of knowledge or skills (41.8\%). Security for online transactions continues to dominate discussions on electronic commerce (Elliot \& Fowell, 2000; Szymanski \& Hise, 2000; Liao $\&$ Cheung, 2001). Consumers are concerned about disclosing their financial and personal information. In addition, the security and reliability aspects of the company are important aspects that are emphasized when making online purchases (Gefen, 2000). Consumers are concerned about disclosing their financial and personal information. Although most online purchase-based sites provide personal 
information protection policies and guarantee transaction security, they do not elaborate on how transactions and personal data will be protected (Elliot and Fowell, 2000). In addition, the risk aspects (products and transactions) are also frequently studied topics (Chang, Cheung \& Lai, 2005). Individuals who avoid online purchases are because they are more concerned with satisfaction at the time of purchase (Chang, Cheung \& Lai, 2005). In addition, consumer experience factors are also considered in online purchase decision making (Hoffman, Novak \& Peralta, 1999).

Furthermore, simple and time-saving factors also influence individuals to buy online through interactions with online displays (Szymanski and Hise, 2000). Meanwhile, a fast, organized and easyto-use side page display will provide maximum satisfaction to users (Chung-Hoon \& Young-Gul, 2003) while providing a good experience for consumers to continue making online purchases with the company (Griffith, Krampf \& Palmer, 2001).

\section{Methodology}

This section outlines the research methodology used. This study uses the survey method. This section will discuss research instruments, sampling procedures and data collection. The research instrument for this study is a two-part questionnaire: Part 1 measures the socio-demographic characteristics of respondents. Among the characteristics measured are generation, gender, stratum, ethnicity, highest level of education, total income of home and zone. In Section 2, closed-ended questions are provided. Respondents were asked if they had purchased online. If ever, respondents are asked to answer the next question about the purchase practice. There are five statements that have been submitted and measured using 5 Likert scales, namely $(1=$ strongly disagree, $2=$ disagree, $3=$ simple, $4=$ agree, $5=$ strongly agree). The analysis of practice levels was performed by calculating the frequency of respondents when making all statements in that section. Scores are then used to obtain practice levels and are categorized into three categories, namely " $1=$ low", " $2=$ medium" and " $3=$ high".

Subsequently, pilot test was conducted among 30 respondents aged 17 - 68 around the Petaling Jaya aimed at looking at respondents' understanding of the questions asked and testing the validity and reliability of the questionnaire developed. Reliability in research refers to the ability of a study to obtain similar values when the same measurement is repeated. The results showed that the Cronbach's Alpha value obtained was 0.652 and was used because the Cronbach's Alpha value was dependent on the number of items. If the number of items is less than ten, then it is normal if the Cronbach value is as low as 0.5 (Pallant, 2010).

The population of this study is the users over the age of 17 because they have experience on online purchase. The selection of respondents is convenience through the mall intercept method. Through this method, individuals at the center of the dispute were selected as respondents without the need for any random selection process as long as they agreed to be respondents. Distributed questionnaire forms are self-administered with 35 minutes of resolution. Each state in Malaysia has been divided into zones, namely the Northern Zone (Perlis, Kedah, Penang and Perak), the Central Zone (Selangor and the Federal Territories including Putrajaya and Kuala Lumpur), the Southern Zone (Negeri Sembilan, Melaka and Johor), the Eastern Zone (Pahang, Terengganu and Kelantan) as well as Sabah and Sarawak. A total of 3600 respondents were involved in this study with each state involving 600 respondents. However, 23 sets of questionnaire forms were not returned in addition to damage to the form. Therefore, only 3577 or 99.3 percent of the set of forms obtained during this study was conducted. Next, the data obtained, is descriptively analyzed for frequency and percentage. Statistical analysis through t-test and ANOVA is also used to compare online purchasing practices with selected background factors (gender, stratum, generation, ethnicity, home income, education level and zone).

\section{Result}

The findings of this study found that 1321 respondents (37.0\%) had previously purchased online. 28.8 percent were late Gen Y (17 - 23 years old), followed by the beginning of Gen Y (31 - 37 years), Gen 
$\mathrm{X}$ (38 - 49 years), which was 25.1 percent and the rest was the Baby Boomer generation (50 - 68 years) which is 16.7 percent. Based on the zone, the study found that 56.6 percent of respondents from the Peninsula bought online followed by Sabah (23.9\%) and Sarawak (19.6\%). In addition, respondents in the city dominated this activity $(64.5 \%)$ compared to rural respondents $(35.5 \%)$. In terms of gender, studies have found that women $(59.8 \%)$ often do this online shopping activity compared to men (40.2\%). This activity was also high among Malaysian respondents (62.4\%), followed by Bumiputera Sabah (16.2\%) and Bumiputera Sarawak (10.8\%). Most of the respondents who performed this activity were married $(56.8 \%)$ and single $(38.5 \%)$. Education levels also show that respondents with higher secondary school, higher education and lower secondary school often spend online, with 71.2 percent, 17.4 percent and 7.5 percent respectively. The results also found that income respondents in the RM 1000 - 3000 environment were the most likely to buy online, up by 31.4 percent, followed by income respondents $\leq$ RM $1000(22.6 \%)$ and RM 3001 - 5000 (20.6\%). This indicates low-capacity respondents and moderate to do this activity is probably because they want to get cheaper goods and services than traditional ones.

\section{Online Purchase Practice Selected Respondents}

Most respondents agreed with the statement 'I bought online because it was cheap' in which $23.2 \%$ of respondents expressed their agreement and $20.3 \%$ of respondents said they strongly agreed. Here indicates that most respondents consider the goods and services to be offered online is cheaper than the goods and services offered by traditional businesses. Respondents also supported the statement 'I bought online because of the fast delivery time' in which $29.2 \%$ of respondents agreed and $21.5 \%$ strongly agreed with this statement. However, there were also respondents who preferred to buy traditionally rather than online where $29.4 \%$ of respondents strongly agreed and $22.3 \%$ of respondents agreed with this statement. This shows that even though respondents shop online, buying traditional shopping remains a top choice in choosing goods and services.

38.1 percent respondents strongly agree with the statement 'make a complaint when dissatisfied with the product purchased online'. This shows respondents who buy online understand and know their rights as consumers where one of the rights of consumers is the right to compensation. By making a complaint, respondents may be compensated for the goods or services purchased if the goods or services are damaged or do not meet the consumer's perception. Statement 'online purchase can be done at any time, regardless of time' is agreed upon by 67 respondents of whom 42 percent of respondents expressed their strongly agree and 25 percent expressed their consent. This shows that buying goods and services online does not require a certain amount of time to buy them, and this also encourages consumers to spend on their own time.

These scores are categorized into three low (5 - 11), medium (12 - 18) and high (19 - 25). The results showed that 48.1 percent of respondents had a moderate level of practice in online purchases. This is probably because the practice of online buying in Malaysia is still new to rural consumers than in the city. In addition, several factors are also taken into account by consumers before undertaking online purchasing activities. These factors are clearly detailed in the next subtopic.

\section{Differences in online purchase practice with selected background factors (gender and generation)}

The findings show that there was a significant difference $(t=-3.156, p=0.001)$ for online purchase practice scores between male and female respondents. This shows that female consumers prefer to buy online than men because they may be due to factors such as flexible purchase times, free shipping of goods and ease of shopping. The findings also show that female consumers are most likely to conduct online buying activities regardless of time and place. However, the findings of this study are contrary to a study conducted by Susskind (2004) that found that men dominate online purchases.

In addition to gender, the stratum is also taken into account to determine whether urban or rural respondents regularly carry out these online buying activities. The results showed that there was no significant difference between urban and rural respondents for online purchase practice scores $(\mathrm{p}>$ 
0.05). This may be because rural users are also easy to access the internet as internet coverage is now growing and accessible in this area.

ANOVA tests have also been conducted to compare online purchase practice scores with respondents. The results of this study are as shown in Table 1 which shows significant average score differences in terms of generation $(F(3,1298)=3.475, p=0.016)$. The results show that early generations of $Y$ and $X$ generations made purchases more often online than other generations (late generations of $\mathrm{Y}$ and Baby Boomers). The findings of this study are in line with a study conducted by Eurostat (2007) that found that 71.0 percent of people aged $55-74$ in Europe did not do any internet-related activity compared to only 11.0 percent of young people. This may be because the widespread exposure to information technology has also increased exposure to online purchases for that generation.

For ethnic groups, the results show that there are very significant differences for each ethnic group studied $(\mathrm{F}(4,1291)=3.678, \mathrm{p}=0.006)$. It is found that Bumiputera Sarawak made more online purchases than any other ethnic group studied. This may be due to the buying factor online is easier and more flexible making Bumiputera Sarawak more likely to shop using this method. So does Bumiputera Sabah. In addition to simple and flexible purchase factors, distance and location factors should also be taken into consideration. Most products purchased online may be difficult to find at the respondent's location, so online purchases are one of the alternatives to obtaining the product and this indirectly enhances the online purchase practices of Bumiputera Sarawak, Sabah and Malay ethnic groups. However, most Indians buy online probably because they do not believe online purchases are true and prefer traditional purchases.

ANOVA tests of home income on online purchase practice scores showed significant differences $(\mathrm{F}(4$, $1227)=6,935, \mathrm{p}=0.000$ ) where the highest average practice score for RM 3000 income respondents and above. This indicates that online purchases are mostly carried out by respondents in the medium and high household income categories. This finding is consistent with recent studies that have found that men, higher education and high-income groups are more likely to buy online (Forsythe \& Shi, 2003; Swinyard \& Smith, 2003). This is possible because respondents earning RM 3000 and above are better able to pay the costs delivery and service costs incurred by the trader when making online purchases compared to low-income respondents.

The results also found that there were no significant differences in the level of education of respondents $(\mathrm{F}(5) 1289)=1.801,, \mathrm{p}=0.110)$ and zones $(\mathrm{F}(2,1286)=1.148, \mathrm{p}=0.318)$ with an average score of purchase practices online. This indicates that respondents' education level does not affect online purchasing practices. However, the highest online buying practice score is among highly educated respondents. This is probably because most well-educated respondents work in environments that need to use computers and the internet and indirectly make it easier for them to use the internet to make purchases. However, the findings are inconsistent with previous studies when aspects of education are seen as affecting internet-related activities when only 12.0 percent of the population with higher education do not perform any internet-related activities compared to 63.0 percent of the population with lower education / no formal education (Eurostat, 2007). The findings conclude that the higher the level of education, the more often individuals use the internet. In terms of zones, although there were no significant differences, it was found that respondents living in Sarawak made more frequent purchases online than respondents living in the Peninsula and Sabah. Therefore, further studies need to be conducted to identify which factors influence Sarawak users in this online purchase activity.

Table 1: ANNOVA test for online practice purchase with selected background factors

\begin{tabular}{lccccc}
\hline \multicolumn{1}{c}{ Construct } & Frequency $(\mathbf{n})$ & $\begin{array}{c}\text { Mean } \\
\text { Score }\end{array}$ & $\begin{array}{c}\text { Std. } \\
\text { Deviation }\end{array}$ & F-Value & P-Value \\
\hline GEN & & & & & \\
Late Gen Y $(17-23$ years old) & 380 & 17.413 & 3.540 & & \\
Early Gen Y (31 - 37 years old) & 377 & 18.110 & 3.733 & $3.475^{*}$ & 0.016 \\
Gen X (38-29 years old) & 330 & 18.198 & 4.537 & & \\
Baby boomer (50-68 years old) & 219 & 17.465 & 4.699 & & \\
\hline
\end{tabular}


DOI: https://doi.org/10.47405/mjssh.v6i10.1089

\begin{tabular}{lccccc}
\hline ZONE & 736 & 17.683 & 4.317 & 1.148 & 0.318 \\
Peninsular Malaysia & 311 & 17.924 & 3.697 & & \\
Sabah & 253 & 18.103 & 3.510 & & \\
Sarawak & & & & & \\
ETHNICITY & 811 & 17.965 & 4.213 & & \\
Malay & 11 & 17.263 & 2.791 & $3.678^{* *}$ & 0.006 \\
Chinese & 28 & 15.321 & 5.150 & & \\
Indian & 213 & 17.791 & 3.786 & & \\
Bumiputra Sabah & 141 & 18.092 & 3.642 & & \\
Bumiputra Sarawak & & & & & \\
EDUCATION LEVEL & 23 & 16.772 & 4.046 & & \\
No Education & 30 & 17.321 & 3.103 & 1.801 & \\
Primary School & 98 & 17.020 & 4.710 & & \\
Lower Secondary School & 928 & 17.837 & 4.075 & & \\
Higher Secondary School & 228 & 18.293 & 3.338 & & \\
Higher Education & & & & & \\
HOUSEHOLD INCOME & 282 & 16.917 & 4.566 & & \\
S RM 1000 & 389 & 17.810 & 4.189 & $6.935^{* * *}$ & 0.000 \\
RM 1001 - 3000 & 256 & 18.226 & 3.575 & & \\
RM 3001 - 5000 & 163 & 18.339 & 3.366 & & \\
RM 5001 - 7000 & 152 & 18.103 & 3.403 & & \\
Z RM 7001 & & & & & \\
\hline
\end{tabular}

\section{Discussion}

\section{Factors affecting respondents when buying online}

There are many factors to consider in conducting online purchasing activities. In this study, nine factors identified are necessary in this online purchase. The following are: security, product offered, risk, user experience/testimonial, home page display, easy and time-saving, reliable, user and promotional services, and seller reputation. The findings show that only five key factors are consumer choice, namely safety factors, products offered, risks, reliability and user experience/testimonials. About $71.3 \%$ of respondents felt that safety factors were crucial in making online purchases. Security means respondents need to provide personal information to the seller and this indirectly increases their security risk. This finding is supported by a recent study conducted by Better Business Bureau in 2001 that showed 72.0 percent of respondents surveyed were "overly concerned" or "very concerned" about the disclosure of personal information after they bought something online. This directly illustrates that the knowledge and awareness aspects of internet issues and security are particularly important in the culture and context of the digital environment.

Furthermore, 53.9\% of respondents were concerned with the product offered by the seller or dealer online. While users may not be able to make a real choice, users can make a selection through the pictures provided by the seller or dealer on their side page. Users can also find out more about products sold over the internet or from other sources. This finding is in line with a study conducted by Liang and Huang (1998) that found that online purchases were dependent on the type of product offered, the risks and experience of the user himself. This is because according to Lohse and Spiller (1998) improvements to the product list have a significant impact on sales where they propose to include pictures of the product they want for sale. Ho and Wu (1999) also state that an accurate picture of the product will provide maximum satisfaction to the user.

In addition, the risk factors were also highlighted by 52.1 percent of respondents. The risk of disclosure of confidential information such as credit card numbers, home addresses, phone numbers and other confidential information may occur if you make an online purchase. The results of this study are in line with a study conducted by Fox (2000) when 86.0 percent of internet users are concerned that there are individuals or companies that are not known to obtain information they go online, another 70.0 percent 
are concerned about the security of credit card numbers and another 60.0 percent are worried that individuals will disclose their personal information that the transaction has taken place over the internet.

Therefore, enforcement of the online sales act should always be done to protect this user's information. In addition, respondents also emphasized the credible factors in making online purchases $(38.2 \%)$. This reliable factor is more relevant to traders or sellers who sell online. Most consumers will buy goods or services from reliable traders or sellers and provide the best service to their customers. This is because the reliability of online dealing is a determining factor in ensuring the success of one-on-one sites in the market (Koufaris \& Hampton-Sosa, 2004). This is because the higher the consumer trust rate, the higher the intention to buy, and the easier it is for companies to retain customers (Jarvenpaa \& Tractinsky, 1999; Gefen \& Straub, 2004). User experience or testimonials of a goods or services will influence other users to purchase such goods or services. This too was a factor that respondents noted in this study in which $32.4 \%$ of respondents chose this factor in their interest when buying online. Similar results were obtained from studies conducted by Hoffman, Novak and Peralta (1999) that found that other user experience factors were also considered in online purchase decision making.

\section{Conclusion}

The results show that the percentage of respondents involved in online purchases is still low, involving only 37.0 percent. In terms of online buying practices, it also shows that they are at a moderate level. Comparison of background aspects also shows that female respondents, X-generation, Bumiputera Sarawak and high-income ethnic groups are more likely to make online purchases. However, differences in stratum, education and zones did not show any differences between respondents. In addition, aspects such as safe service, product diversity, risk factors, reliability and consumer testimonials are what respondents consider when making online purchases.

Therefore, this study has implications for sellers to focus more on target users such as emphasizing aspects of delivery speed, improving website display by providing accurate and complete information. Sellers also need to focus on marketing strategies so that they can understand potential buyers' behavior. In addition, safe, reliable services, a wide range of products offered and secure transactions are necessary to attract new buyers while maintaining existing buyers. From a consumer point of view, they are always equipped with the knowledge to avoid being fooled by online purchases. This is because despite the growing online sales, there have also been several complaints made by consumers in various aspects to the National Consumer Complaints Service Center (NCCC). This shows that despite the rapid growth of online purchases, there are still weaknesses in the security and privacy aspects of consumers. Also, access to internet usage is necessary enhanced and expanded throughout the region to reduce the internet usage gap for urban and rural users.

\section{References}

Better Business Bureau (2001). Third party assurance boosts online purchasing. http://www.bbbonline.org/about/press/2001/101701.asp

Chang, M., K., Cheung, W., \& Lai, V., S. (2005). Literature derived reference models for the adoption of online shopping. Information and Management, 42(4), 543-559.

Chung-Hoon, P. \& Young-Gul, K. (2003). Identifying key factors affecting consumer purchase behavior in an online shopping context. International Journal of Retail and Distribution Management, 31(1), 16-29.

Citrin, A. V., Stem Jr., D. E., Spangenberg, E. R. \& Clark, M. J. (2003). Consumer need for tactile input: An internet retailing challenge. Journal of Business Research, 56(11), 915- 923.

Department of Statistics Malaysia (2021). ICT Use and Access by Individuals and Households Survey Report $2013 \quad$ Retrieved from https://www.dosm.gov.my/v1/images/stories/files/LatestReleases/ICT_Use/2013/LaporanP P \& C_ICT_2013.pdf 
Elliot, S. \& Fowell, S. (2000). Expectations versus reality: A snapshot of consumer experiences with Internet retailing. International Journal of Information Management, 20(5), 323-336.

Eurostat (2007), data accessed from the Eurostat database at http://epp.eurostat.ec.europa.eu/

Forsythe, S. M. \& Shi, B. (2003). Consumer patronage and risk perceptions in internet shopping. Journal of Business Research, 56, 867-875.

Fox, S. (2000). Trust and privacy online: "Why Americans want to rewrite the rules", Pew Internet and American Life Project, available at http://www.pewinternet.org

Gefen, D. (2000). E-commerce: The role of familiarity and trust. Omega, 28(6), 725-737.

Gefen, D. dan Straub, D.W. (2004). Consumer trust in B2C e-commerce and the importance of social presence: Experiments in e-products and e-services. Omega, 32, 407-24.

Griffith, D. A., Krampf, R. F., \& Palmer, J. W. (2001). The role of interface in electronic commerce: Consumer involvement with print versus online catalogs. International Journal of Electronic Commerce, 5(4), 135-53.

Harian Metro (2013, July 3). Wanita paling mudah ditipu. Retrieved from http://mobile.hmetro.com.my/articles/Wanitapalingmudahditipu/2013/Article

Ho, C. F. \& Wu, W. H. (1999). Antecedents of customer satisfaction on the internet: An empirical study of online shopping. in Proc. 32nd Hawaii Int. Conf. System Sciences.

Hoffman, D. L., Novak, T. P., \& Peralta, M. (1999). Building consumer trust online. Communications of the ACM, 42(4), 80-5.

Jarvenpaa, S.L. \& Tractinsky, N. (1999). Consumer trust in an internet store: a cross-cultural validation. Journal of Computer Mediated Communication, 5(2),1-35.

Koufaris, M. \& Hampton-Sosa, W. (2004). The development of initial trust in an online company by new customers. Information and Management, 41, 377-97.

Li, H., Kuo, C., \& Russell, M. G. (1999). The impact of perceived channel utilities, shopping orientations and demographics on the consumer's online buying behavior. Journal of Computer Mediated Communication, 5, 23-50.

Li, N., \& Zhang, P. (2002). Consumer Online Shopping Attitudes and Behavior: An Assessment of Research. Eighth Americas Conference on Information Systems, 508-517.

Liang, T. P. \& J. S. Huang, J. S. (1998). An empirical study on consumer acceptance of products in electronic markets: A transaction cost model. Decision Support Systems, 24(1), 29-43.

Liao, Z. \& Cheung, M. T. (2001). Internet-based e-shopping and consumer attitudes: An empirical study. Information and Management, 38(5), 299-306.

Lohse, G. \& Spiller, P. (1998). Quantifying the effect of user interface design features on cyberstore traffic and sales. CHI'98 Conf. Proc.. Los Alamitos, CA, 1998b.

Ministry of Finance (2014). Prestasi Ekonomi dan Kerjasama Antarabangsa 2013/2014. Retrieved from https://www.mof.gov.my/arkib/ekonomi/2014/bab2.pdf

Pallant, J. (2010). SPSS Survival Manual. Fourth Edition. England: Mc Graw Hill.

Rodgers, S. \& Harris, M. (2003). Gender and E-Commerce: An exploratory study. Journal of Advertising Research, 43(3), 322-330.

Susskind, A. (2004). Electronic commerce and World Wide Web apprehensiveness: An examination of consumers' perceptions of the World Wide Web. Journal of Computer-Medicated Communication, 9(3), 78-90.

Swinyard, W. R. \& Smith, S.M. (2003). Why people (don't) shop online: A lifestyle study of the internet consumer. Psychology and Marketing, 567-597.

Szymanski, D. M. \& Hise, R. T. (2000). E-satisfaction: An initial examination. Journal of Retailing, $76(3), 309-22$.

$\mathrm{Wu}$, S. L. (2003). The relationship between consumer characteristics and attitude toward online shopping. Marketing Intelligence and Planning, 21, 37-44. 